\title{
Pengembangan Sistem Pengaturan Larutan Nutrisi Otomatis Pada Budidaya Kentang Aeroponik
}

\section{Development of Automatic Nutrient Solution Regulatory System in Aeroponic Potato Cultivation}

WULANDARI $^{1 *}$, NENG WINA SUMIAR ${ }^{1}$

\begin{abstract}
Abstrak
Penerapan teknik aeroponik pada budidaya kentang dapat menjadi salah satu metode alternatif yang dapat digunakan untuk mengatasi keterbatasan lahan. Selain itu, teknik ini juga dapat digunakan untuk meningkatkan produktivitas tanaman tersebut. Akan tetapi, pemberian nutrisi dan proses penyiraman pada teknik ini masih dilakukan secara manual. Teknik yang digunakan saat ini yaitu pengontrolan nutrisi menggunakan alat ukur yang memerlukan sumber daya manusia. Salah satu tantangan dalam budidaya ini yaitu perlunya pemantauan dan pengaturan nutrisi yang optimal. Wadah aeroponik perlu dipantau secara berkala dan berkelanjutan. Oleh karena itu, dikembangkan sistem otomatisasi pengaturan larutan nutrisi pada budidaya kentang secara aeroponik. Sistem otomatisasi ini diharapkan dapat menciptakan kondisi ideal bagi tanaman, karena alat tersebut mampu mengatur kadar larutan nutrisi yang optimal. Berdasarkan hasil pengujian, sensor Total Dissolved Solids (TDS) mampu mengukur kadar larutan nutrisi campuran dengan akurasi 98.28\%. Selain itu, sensor ultrasonik mampu membaca ketinggian air sesuai dengan jarak yang sesungguhnya pada semua pengujian yang dilakukan. Aktuator pergerakan sensor TDS bekerja sesuai dengan skenario yang dikembangkan. Pergerakan tersebut ditujukan untuk memperpanjang usia guna dari sensor yang digunakan. Aktuator bergerak turun ke arah larutan nutrisi ketika jam sistem benilai genap dan bergerak ke atas ketika jam sistem bernilai ganjil. Secara keseluruhan, sistem dapat bekerja dengan baik sesuai dengan rancangan yang dibuat.
\end{abstract}

Kata Kunci: aeroponik, kentang, sistem otomatis, sensor, TDS, ultrasonik.

\begin{abstract}
The application of aeroponic techniques in potato cultivation can be an alternative method that can be used to overcome land limitations. In addition, this technique can also be used to increase the productivity of these plants. However, the nutrition and watering process in this technique is still done manually. The method currently used is controlling nutrition using measuring instruments that require human resources. One of the challenges in this cultivation is the need for optimal nutrition monitoring and regulation. Aeroponic containers need to be monitored regularly and continuously. Therefore, an automation system for managing nutrient solutions in aeroponic potato cultivation was developed. This automation system is expected to create ideal conditions for plants because the tool is designed to regulate optimal nutrient solution levels. Based on the test results, the Total Dissolved Solids (TDS) sensor is able to measure the levels of the mixed nutrient solution with an accuracy of 98.28\%. In addition, the ultrasonic sensor successfully read the water level according to the actual distance on all tests carried out. The TDS sensor movement actuator works according to the developed scenario. This movement is intended to extend the useful life of the sensors used. The actuator moves down towards the nutrient solution when the system clock is even and moves up when the system clock is odd. Overall, the system can work well in accordance with the design made.
\end{abstract}

Keywords: aeroponics, automatic systems, potato, sensors, TDS, ultrasonic.

\section{PENDAHULUAN}

Salah satu tantangan agroindustri di era 4.0 ini adalah keterbatasan lahan untuk pertanian. Jumlah penduduk Indonesia yang diproyeksikan semakin meningkat setiap tahunnya (BPS

${ }^{1}$ Departemen Ilmu Komputer IPB, 0251-8625584

*Penulis Korespondensi: Tel/Faks: 0251-8625584; Surel: wulandari.ilkom@apps.ipb.ac.id 
2015) mengakibatkan peningkatan pada kebutuhan pemukiman (Setyorini 2012) dan konsumsi. Hal ini menyebabkan alih fungsi dari lahan pertanian menjadi pemukiman penduduk. Selain itu, peningkatan infrastruktur seperti jalan raya juga merupakan salah satu faktor berkurangnya alokasi lahan pertanian. Oleh karena itu, urban farming (hidroponik, aquaponik, dan veltikultur) merupakan salah satu alternatif yang dapat digunakan untuk meningkatkan jumlah produksi pangan. Salah satu produk pangan yang digemari di Indonesia yaitu kentang, karena mudah diolah dan memiliki nilai kandugan karbohidrat yang tinggi.

Kentang (Solanum tuberosum L.) termasuk famili terung-terungan dan merupakan salah satu komoditas sayuran yang banyak mendatangkan keuntungan bagi petani, mempunyai dampak baik dalam pemasaran dan ekspor, tidak mudah rusak seperti sayuran lain, dan merupakan sumber kalori, protein dan juga vitamin (Diwa et al. 2015). Kentang merupakan sayuran umbi dan dipanen bagian umbinya sebagai sumber karbohidrat pengganti nasi. Varietas yang dianjurkan dalam penanaman tanaman kentang adalah Granola, Atlantik, Manohara, Krespo, atau varietas lainnya yang tahan terhadap penyakit busuk daun/layu bakteri. Varietas tanaman kentang yang sangat mendominasi untuk saat ini adalah Granola sebagai kentang sayur dan Atlantik sebagai kentang olahan (Diwa et al. 2015). Tanaman kentang menghendaki kondisi iklim yang ideal dengan suhu rata-rata harian antara 18 sampai 24 derajat Celsius, kelembaban 70 sampai 90 persen, dan sinar matahari 15 sampai 18 derajat (Gunawan 2009; Ruchjaniningsih et al. 2019).

Di Jawa Barat, beberapa daerah yang membudidayakan kentang yaitu Bogor, Bandung (Utami et al. 2015), dan di Kecamatan Pangalengan (Ummah dan Purwito 2009) dan Lembang (Sutrisna dan Lembang 2014) di Kabupaten Bandung Barat. Masalah yang sering muncul pada penanaman di daerah dataran rendah tersebut yaitu sulitnya mencari bibit kentang dengan kualitas unggul. Benih bermutu dan varietas unggul dapat menghasilkan tingkat keseragaman yang tinggi, berproduktivitas tinggi dan sehat (Diwa et al. 2015). Selain itu, hal tersebut juga dapat memengaruhi resistensi terhadap hama. Salah satu metode yang dapat digunakan untuk meningkatkan produktivitas yaitu dengan menggunakan metode aeroponik.

Aeroponik merupakan merupakan suatu cara bercocok tanam yang tidak jauh berbeda dengan sistem hidroponik yaitu memanfaatkan air untuk pemberian nutrisi pada tanaman (Setiawan 2019). Hanya saja, teknik aeroponik memerlukan air yang sudah berisi larutan hara yang nantinya akan disemprotkan dengan menggunakan pompa bertekanan tinggi menggunakan sprinkler ke bagian akar tanaman dalam bentuk kabut (Sutiyoso 2003). Selanjutnya, akar tanaman yang ditanam dibiarkan menggantung sehingga dapat menyerap larutan nutrisi. Waktu terbaik untuk irigasi aeroponik adalah 10 detik setiap 15 menit sekali dan harus beroperasi selama 24 jam. Hal ini bertujuan agar akar tetap lembab dan kebutuhan nutrisi pada tanaman kentang tercukupi (Mbiyu 2012). Penerapan metode aeroponik pada budidaya kentang telah dilakukan oleh Sumarni et al. (2013). Berdasarkan penelitian tersebut, metode aeroponik dapat digunakan untuk budidaya kentang di dataran rendah.

Salah satu tantangan dalam penerapan budidaya aeroponik pada kentang (Dianawati 2013; Otazu 2010) yaitu perlunya pemantauan dan pengaturan nutrisi yang optimal. Wadah aeroponik perlu dipantau secara berkala dan berkelanjutan. Selain itu tingkat sanitasi yang baik pada greenhouse atau screen house harus terjaga. Salah satu kunci proses aeroponik adalah oksigenasi dari butiran kabut halus yang membawa zat hara atau nutrisi sampai ke akar (Siregar dan Rivai 2019). Pada metode ini, nutrisi diberikan tanaman dengan menggunakan larutan nutrisi yang disemprotkan. Larutan nutrisi tersebut terdiri dari nutrisi A dan Nutrisi B. Nutrisi A memiliki kandungan calcium nitrat, Fe7, dan kalium nitrat sedangkan untuk nutrisi $\mathrm{B}$ memiliki kandungan $\mathrm{KH} 2 \mathrm{PO}$, mono ammonium fosfat, kalium sufat, magnesium sulfat, manganium sulfat, cupro sulfat, zinc sulfat, asam borat, amonium hepta molybdat atau natrium molybdat (Sutiyoso 2003). Pemberian nutrisi yang teratur sangat penting pada aeroponik, karena media hanya berfungsi sebagai penopang tanaman dan sarana meneruskan larutan atau air ke akar tanaman tersebut. Pemberian nutrisi yang sesuai untuk penanaman kentang yaitu dengan pemberian nutrisi secara bertahap yakni berkisar antara 1250-1850 ppm (Amsah 2017). 
Penelitian ini bertujuan untuk mengembangkan sebuah sistem pengaturan otomatis untuk pemberian larutan nutrisi pada budidaya kentang aeroponik. Pengaturan otomatis telah dilakukan sebelumnya oleh Montoya et al. (2017) dan Kerns dan Lee (2017). Penelitian tersebut mengembangkan sistem otomatis untuk memantau kadar $\mathrm{pH}$ dan electrical conductivity sensor, selanjutnya hasil pembacaan sensor tersebut dikirimkan ke server. Namun, pengaturan kadar larutan nutrisi masih dilakukan secara manual. Pada penelitian ini, sistem yang dikembangkan berupa prototipe sistem pemantauan dan pengaturan kadar nutrisi pada larutan nutrisi budidaya aeroponik dengan satu lubang tanam. Sistem akan mengatur kadar larutan nutrisi pada wadah larutan campuran secara otomatis dengan cara mengukur kadar larutan menggunakan sensor Total Dissolved Solids (TDS). Ketika larutan campuran memiliki kadar yang lebih rendah atau lebih tinggi dari ambang batas, maka sistem akan mencampurkan larutan pekatan A, larutan pekatan B, dan air secara otomatis sampai mencapai rentang yang telah diatur sebelumnya. Selain itu, sensor ultrasonik digunakan untuk memantau ketinggian dari larutan pada wadah.

\section{METODE}

Metode yang digunakan pada penelitian ini ditunjukkan pada Gambar 1. Tahapan tersebut terdiri dari analisis masalah dan kebutuhan sistem, perancangan sistem, implementasi sistem, pengujian dan evaluasi.

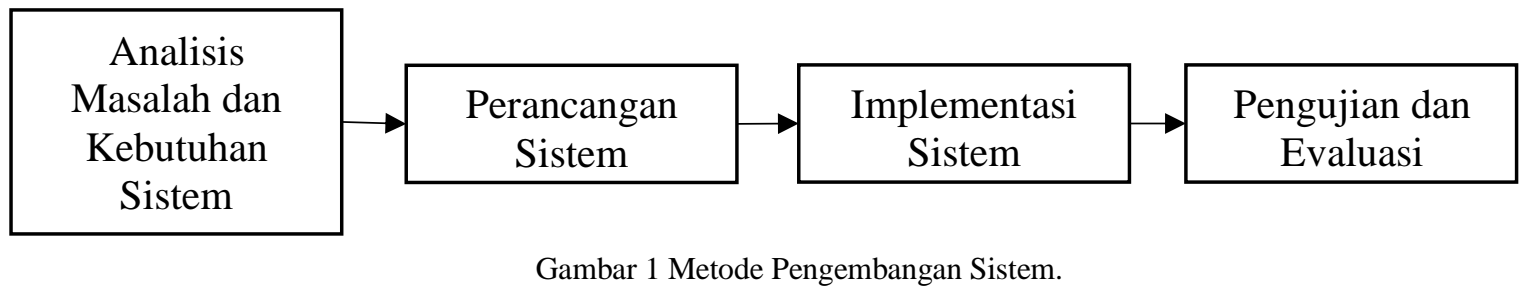

\section{Analisis Masalah dan Kebutuhan Sistem}

Tahap analisis bertujuan untuk mengetahui permasalahan dan kebutuhan yang diperlukan untuk pengembangan sistem. Pada tahapan ini dilakukan analisis kebutuhan dengan merinci komponen yang dibutuhkan untuk pembuatan alat dan nutrisi untuk tanaman.

\section{Perancangan Sistem}

Pada tahap perancangan ini, dilakukan pembuatan blok diagram alat serta flowchart kerja sistem. Selain itu, pada tahap perancangan juga dilakukan pembuatan skema rangkaian perangkat keras alat.

\section{Implementasi Sistem}

Tahap implementasi merupakan tahap penerapan dari seluruh analisis dan rancangan yang telah dibuat. Pembuatan alat sistem pengaturan nutrisi dan pemantauan pertumbuhan akar kentang menggunakan teknik aeroponik dilakukan pada tahap ini.

\section{Pengujian dan Evaluasi}

Tahap pengujian ini dilakukan untuk mengetahui kesesuaian hasil uji alat dengan tujuan yang telah ditetapkan. Pada tahapan ini dilakukan evaluasi dengan menjalankan fungsi alat sesuai dengan flowchart yang telah dirancang sebelumnya. Sistem dievaluasi dengan menggunakan parameter persentase error dan akurasi (Persamaan 1 dan Persamaan 2).

$$
\begin{gathered}
\% \text { error }=\frac{\mid \text { Nilai pembanding }- \text { Nilai pengukuran } \mid}{\text { Nilai pembanding }} \times 100 \% \\
\text { Akurasi }=100 \%-\% \text { error }
\end{gathered}
$$

dengan nilai pembanding merupakan nilai pengukuran TDS meter, dan nilai pengukuran meupakan nilai keluaran sensor TDS. 


\section{HASIL DAN PEMBAHASAN}

\section{Analisis Masalah dan Kebutuhan Sistem}

Budidaya kentang dengan teknik aeroponik membutuhkan pemberian larutan nutrisi yang diberikan dengan menggunakan spray. Larutan nutrisi tersebut perlu diukur secara manual dengan menggunakan TDS meter. Tahapan tersebut cukup menyulitkan petani karena diperlukan pengukuran yang sesuai dengan kadar yang dibutuhkan oleh tanaman. Selain itu, tidak optimalnya kadar larutan nutrisi yang diberikan dapat mengakibatkan turunnya kualitas pada tanaman. Kadar larutan nutrisi yang sesuai untuk tanaman kentang yaitu berkisar antara 1250-1850 ppm. Berdasarkan hal tersebut, dirancang sebuah sistem yang dapat mencampurkan larutan nutrisi dengan kadar yang sesuai secara otomatis. Tahap ini dilakukan analisis kebutuhan alat dan bahan yang diperlukan untuk membangun sistem tersebut. Kebutuhan perangkat keras dan lunak yang diperlukan untuk pengembangan sistem ini ditampilkan pada Tabel 1 dan Tabel 2. Arduino Mega 2560 dipilih sebagai perangkat pemrosesan dari sistem ini karena board tersebut memiliki jumlah pin yang cukup banyak dan memiliki kemampuan komputasi yang cukup untuk memroses masukan dari sensor yang digunakan.

Tabel 1 Daftar kebutuhan perangkat keras

\begin{tabular}{|c|c|c|c|}
\hline No & Kebutuhan & Pin yang digunakan & Keterangan \\
\hline 1 & Arduino Mega 2560 & - & $\begin{array}{l}\text { Memproses perintah masukan dan keluaran sesuai kode } \\
\text { program }\end{array}$ \\
\hline 2 & Servo MG996 & D5 & Aktuator penggerak sensor TDS \\
\hline 3 & Sensor Ultrasonik HC-SR04 & D6, D7 & Pengukur jarak antara sensor TDS dengan tinggi air nutrisi \\
\hline 4 & Real Time Clock DS3231 & SDA, SCL & $\begin{array}{l}\text { Pengatur waktu untuk gerak aktuator dan mengatur kapan } \\
\text { pompa DC High Pressure menyala }\end{array}$ \\
\hline 5 & Relay 4 Channel & D8, D9, D10, D11 & $\begin{array}{l}\text { Saklar atau switch yang mengatur peristaltic pump akan } \\
\text { menyala }\end{array}$ \\
\hline 6 & $\begin{array}{l}\text { Pompa DC High Pressure } \\
12 \mathrm{~V}\end{array}$ & D11 (Relay) & $\begin{array}{l}\text { Pompa yang mengalirkan air nutrisi } \mathrm{AB} \text { mix untuk } \\
\text { pengkabutan }\end{array}$ \\
\hline 7 & Peristaltic Pump 12V & D8, D9 (Relay) & $\begin{array}{l}\text { Pompa di pin } D 8 \text { untuk mengalirkan air nutrisi A ke } \\
\text { tandon } A B \text { mix, pompa di pin D9 untuk mengalirkan air } \\
\text { nutrisi } B \text { ke tandon } A B \text { mix. }\end{array}$ \\
\hline 8 & Pompa DC $12 \mathrm{~V}$ & D10 (Relay) & Pompa untuk mengalirkan air ke wadah nutrisi $\mathrm{AB}$ mix \\
\hline 9 & TDS sensor & A0 & $\begin{array}{l}\text { Pengukur nutrisi AB Mix berdasarkan tingkat kepekatan } \\
\text { pada larutan }\end{array}$ \\
\hline 10 & LCD $20 \times 4$ & SDA, SCL & Menampilkan nilai nutrisi \\
\hline 11 & Power Adaptor 12V 3A & - & Sebagai catu daya utama \\
\hline 12 & Power Adaptor $12 \mathrm{~V} 2 \mathrm{~A}$ & - & Sebagai catu daya Pompa DC High Pressure \\
\hline
\end{tabular}

Tabel 2 Daftar kebutuhan perangkat lunak

\begin{tabular}{cll}
\hline No & Perangkat Lunak & \multicolumn{1}{c}{ Keterangan } \\
\hline 1 & ArduinoIDE & Aplikasi untuk compiler dan uploader suatu sketch ke mikrokontroler \\
2 & Fritzing & Aplikasi untuk membuat desain rangkaian \\
3 & Tinkercad & Aplikasi untuk membuat desain 3D \\
4 & Ultimaker Cura & Aplikasi untuk membuat desain 3D dan mengubah format desain 3D \\
\hline
\end{tabular}

\section{Perancangan Sistem}

Pada tahap ini dilakukan perancangan sistem pengaturan larutan nutrisi secara otomatis. Perancangan ini terdiri dari desain perangkat keras dan perangkat lunak. Desain perangkat keras terdiri dari desain alat sistem aeroponik dan rangkaian elektronik yang akan digunakan. Desain perangkat lunak ditampilkan dengan flowchart dan blok diagram. Alat aeroponik terdiri dari sebuah kotak akrilik dengan dimensi panjang $42 \mathrm{~cm}$, lebar $29 \mathrm{~cm}$ dan tinggi $20 \mathrm{~cm}$, yang digunakan sebagai tempat penyemprotan nutrisi pada akar tanaman, netpot dengan diameter 8 cm sebagai wadah akar tanaman. Selanjutnya, kotak akrilik tersebut ditopang dengan besi siku lubang yang dirakit sedemikian rupa untuk menopang wadah dan proses sirkulasi airnya. Pada bagian bawah akrilik diberi lubang yang berdiameter $8 \mathrm{~mm}$ yang kemudian diberi selang yang terhubung ke wadah nutrisi untuk proses sirkulasi air. Pemasangan selang $6 \mathrm{~mm}$ untuk saluran irigasi akrilik diberi lubang di kedua sisi untuk tempat mist nozzle melakukan pengkabutan. Tiga buah wadah air digunakan untuk pencampuran larutan. Wadah utama digunakan sebagai 
penampung larutan nutrisi dan air, dan dua wadah untuk larutan pekatan A dan larutan pekatan nutrisi B untuk hidroponik. Desain perangkat keras berupa perakitan alat ditunjukkan oleh Gambar 2.

Sistem ini dikembakngkan dengan blok diagram untuk pengaturan larutan nutrisi. Blok diagram tersebut menjelaskan proses kerja alat untuk sistem pengaturan larutan nutrisi. Sistem tersebut menggunakan Arduino Mega 2560 sebagai alat komputasi (Gambar 3). Sensor TDS digunakan untuk mendeteksi kadar larutan nutrisi dalam satuan part per million (PPM). Sensor ultrasonik digunakan untuk menghitung jarak antara permukaan larutan nutrisi dan TDS sensor. Jarak tersebut digunakan untuk memberikan informasi ketinggian air yang tersisa pada wadah dan juga untuk menentukan putaran servo untuk menurunkan TDS sensor. Servo MG996 merupakan aktuator yang digunakan untuk menurunkan dan menaikkan sensor TDS. Servo akan bergerak berdasarkan hasil proses perhitungan jarak yang didapatkan sebelumnya. Liquidcrystal display (LCD) akan menampilkan hasil pembacaan dari sensor TDS dan sensor ultrasonik. Relay sebagai saklar untuk menyalakan dan mematikan pompa.

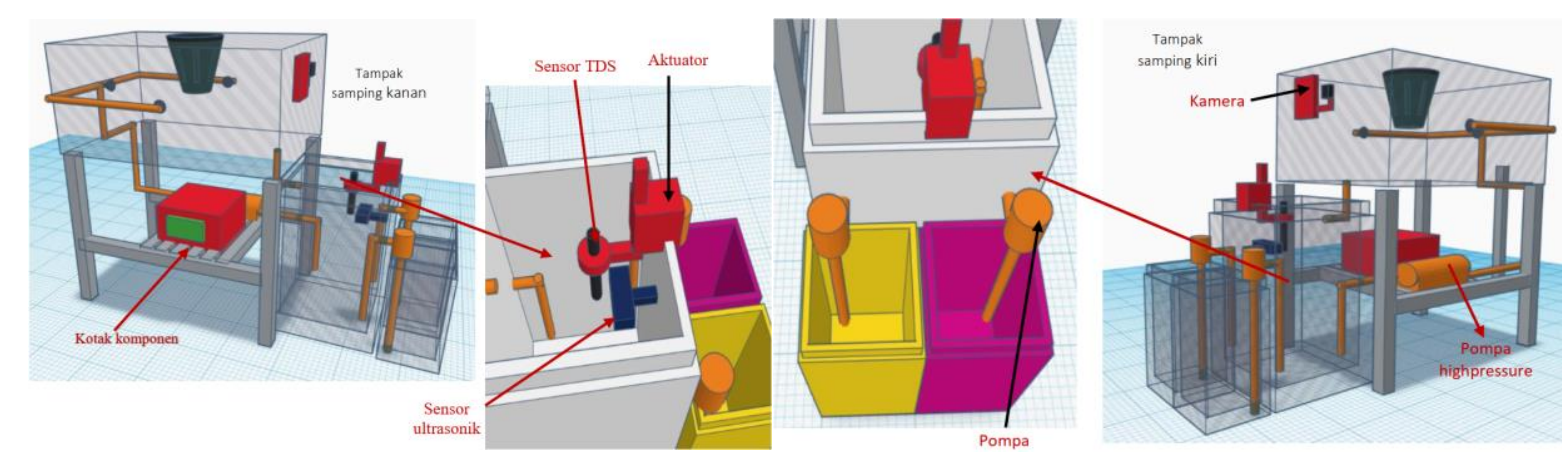

Gambar 2 Desain sistem pengaturan larutan nutrisi dan pemantauan akar.

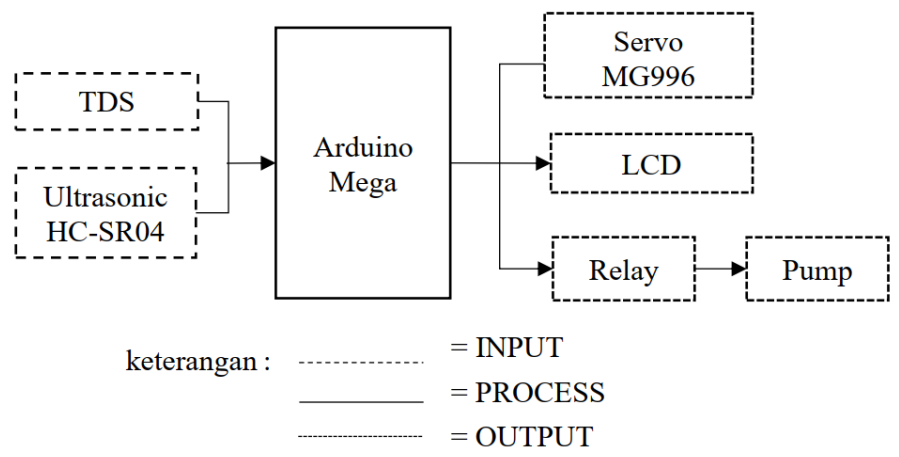

Gambar 3 Blok Diagram Sistem Pengatur Nutrisi.

Flowchart sistem pengaturan nutrisi dan pemantauan pertumbuhan akar kentang menggunakan teknik aeroponik ditunjukkan oleh Gambar 4. Sensor yang terpasang pada sistem ini yaitu sensor TDS untuk mengukur kepekatan nutrisi, sensor ultrasonik mengukur tinggi air pada wadah nutrisi, servo digunakan sebagai aktuator penggerak sensor TDS, Real Time Clock berfungsi sebagai penyimpan waktu dan tanggal, dan relay sebagai saklar pompa. Perawatan sensor TDS perlu dilakukan secara rutin. Sensor konduktivitas dengan perawatan yang baik bisa berusia mencapai 1 hingga 3 tahun. Beberapa faktor yang dapat merusak sensor TDS yaitu pengukuran larutan pada suhu tinggi dan jangka waktu lama tanpa perawatan. Hal ini menyebabkan penumpukan kotoran pada sensor dan pembacaan sensor tidak akurat serta usia sensor tidak tahan lama. Untuk memperkecil permasalahan tersebut perlu adanya treatment pada sensor yaitu dengan pembatasan penggunaan sensor setiap 1 jam sekali selama 24 jam (Zulfikar dan Paring 2016).

Pada sistem ini, perawatan tersebut dilakukan setiap interval satu jam. Hal ini bertujuan untuk memperpanjang usia (life-time) dari sensor TDS. Servo akan aktif dan berputar sejauh 180 derajat pada interval jam bernilai ganjil dan sensor TDS akan bergerak turun menuju larutan 
nutrisi. Kondisi kedua yaitu ketika waktu memasuki jam kerja bernilai ganjil (misalnya jam 01.00 WIB, 03.00 WIB) servo akan aktif dan berputar ke arah nol derajat, sehingga sensor TDS akan bergerak ke atas permukaan larutan nutrisi. Selanjutnya, sensor TDS mengukur kepekatan larutan nutrisi tersebut. Jika kepekatan nutrisi kurang dari ambang batas, pompa pada wadah larutan pekatan nutrisi A dan larutan pekatan nutrisi B akan menyala sampai kadar ppm yang terbaca pada larutan nutrisi campuran mencapai ambang batas. Sebaliknya, jika kadar TDS dalam larutan campuran nutrisi melebihi ambang batas, pompa nutrisi A dan B akan mati, dan pompa air menyala.

Sensor ultrasonik digunakan untuk mengukur jarak antara tinggi air dengan sensor. Hal ini bertujuan untuk menjaga volume air agar tidak berkurang atau melebihi kapasitas wadah larutan nutrisi. Jika nilai dari sensor ultrasonik melebihi ambang batas, hal ini menunjukan volume larutan pada wadah campuran nutrisi kurang, sehingga pompa pada larutan pekatan nutrisi dan pompa air akan menyala. Keluaran yang dibaca oleh sensor TDS, sensor ultrasonik, waktu dan tanggal akan ditampilkan pada LCD.

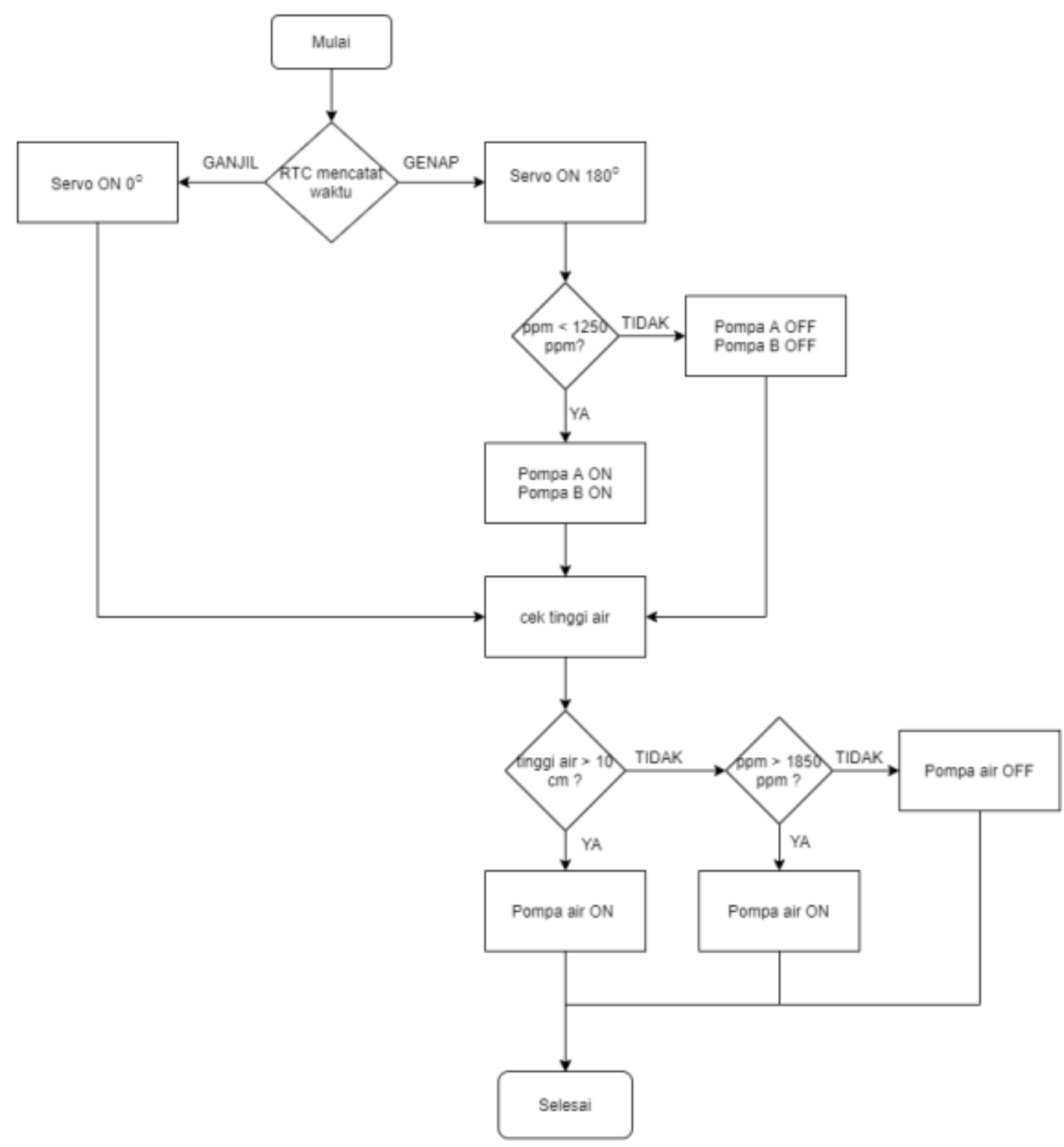

Gambar 4 Flowchart Sistem Pengaturan Larutan Nutrisi.

Skema rangkaian elektronika pada penelitian ini ditunjukkan pada Gambar 5. Skema rangkaian ini dibuat menggunakan perangkat lunak Fritzing versi 0.9.3. Skema rangkaian dibuat untuk menentukan hubungan pin-pin pada komponen dengan mikrokontroler yang digunakan. 


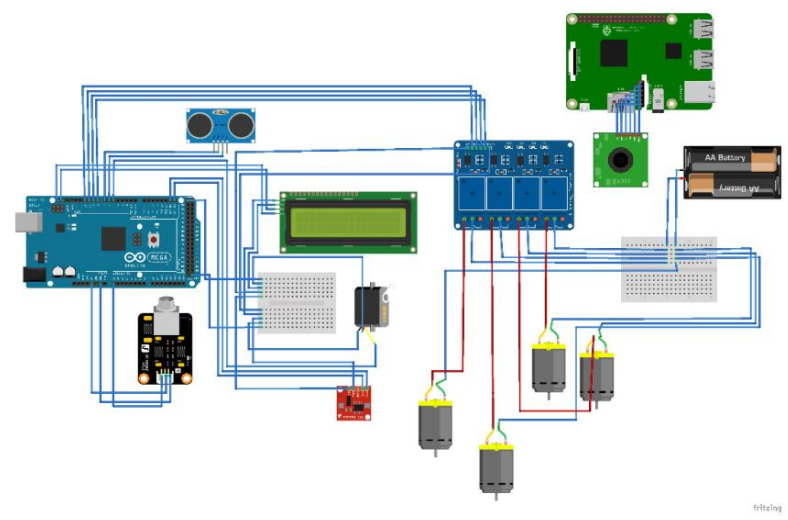

Gambar 5 Skema Rangkaian Sistem.

Tabel 3 menunjukkan hubungan antar kaki pin Arduino Mega 2560 sebagai mikrokontroller dengan sensor TDS. Terdapat tiga buah pin sensor TDS yaitu pin VCC, pin GND dan pin A sebagai input analog yang dihubungkan dengan Arduino Mega 2560. Tabel 4 menunjukkan hubungan antar kaki pin Arduino Mega 2560 sebagai mikrokontroler dengan sensor ultrasonik. Empat buah pin sensor ultrasonik yaitu pin VCC, pin GND pin Trig dan pin Echo dihubungkan dengan Arduino Mega 2560. Koneksi antara kaki pin Arduino Mega 2560 sebagai mikrokontroller dengan modul real time clock (RTC) DS3231 ditunjukkan pada Tabel 5. Empat buah pin yang tersedia pada modul DS3231 yaitu pin VCC, pin GND, pin SDA dan pin SCL yang dihubungkan dengan Arduino Mega 2560. Tabel 6 menunjukkan hubungan antar kaki pin Arduino Mega 2560 sebagai mikrokontroller dengan servo MG996. Tiga buah pin servo MG996 yaitu pin VCC, pin GND dan pin IN sebagai input yang dihubungkan dengan Arduino Mega 2560. Hubungan antar kaki pin Arduino Mega 2560 sebagai mikrokontroller dengan modul i2c LCD ditunjukkan pada Tabel 7. Terdapat empat buah pin modul I2C LCD yaitu pin VCC, pin GND, pin SDA dan pin SCL yang dihubungkan dengan Arduino Mega 2560. Pada Tabel 8 menunjukkan hubungan antar kaki pin Arduino Mega 2560 sebagai mikrokontroller dengan relay. Terdapat enam buah pin relay yaitu pin VCC, pin GND, pin IN1, pin IN2, pin IN3, pin IN3 dan pin IN4 sebagai input yang dihubungkan dengan Arduino Mega 2560 .

Tabel 3 Hubungan kaki Pin Arduino Mega 2560 dengan sensor TDS

\begin{tabular}{ll}
\hline Arduino Mega 2560 & Sensor TDS \\
\hline Pin 5V & Pin VCC \\
Pin GND & Pin GND \\
Pin A0 & Pin A \\
\hline
\end{tabular}

Tabel 5 Hubungan kaki Pin Arduino Mega 2560 dan RTC

\begin{tabular}{ll}
\multicolumn{1}{c}{$\begin{array}{c}\text { Arduino Mega } \\
2560\end{array}$} & \multicolumn{1}{c}{ Modul real time clock (RTC) } \\
DS3231
\end{tabular}

Tabel 7 Hubungan kaki Pin Arduino Mega 2560 dan LCD

\begin{tabular}{ll}
\hline $\begin{array}{c}\text { Arduino Mega } \\
2560\end{array}$ & Modul I2C liquid crystal display \\
(LCD)
\end{tabular}

Tabel 4 Hubungan kaki Pin Arduino Mega 2560 dan sensor Ultrasonik

\begin{tabular}{ll}
\hline Arduino Mega 2560 & Sensor Ultrasonik \\
\hline Pin 5V & Pin VCC \\
Pin GND & Pin GND \\
Pin Trig & Pin D6 \\
Pin Echo & Pin D7 \\
\hline
\end{tabular}

Tabel 6 Hubungan kaki Pin Arduino Mega 2560 dan servo

\begin{tabular}{ll}
\hline Arduino Mega 2560 & Servo MG996 \\
\hline Pin 5V & Pin VCC \\
Pin GND & Pin GND \\
Pin IN & Pin D5 \\
\hline
\end{tabular}

Tabel 8 Hubungan kaki Pin Arduino Mega 2560 dan Relay

\begin{tabular}{ll}
\hline Arduino Mega 2560 & Relay 4 channel \\
\hline Pin 5V & Pin VCC \\
Pin GND & Pin GND \\
Pin IN1 & Pin D8 \\
Pin IN2 & Pin D9 \\
Pin IN3 & Pin D10 \\
Pin IN4 & Pin D11 \\
\hline
\end{tabular}




\section{Implementasi Sistem}

Implementasi alat sistem pengaturan nutrisi tanaman kentang menggunakan teknik aeroponik dilakukan berdasarkan perancangan yang telah dibuat. Pada tahap ini setiap komponen dipasang sesuai dengan rancangan pada proses perancangan mulai dari perancangan rekontruksi alat, blok diagram, flowchart hingga perancangan skema rangkaian. Tahap pemasangan alat dimulai dengan menghubungkan semua perangkat keras yang digunakan dalam pembangunan sistem ini menjadi satu kesatuan, dalam hal ini perangkat keras yang digunakan yaitu akrilik, besi siku lubang, wadah nutrisi campuran, wadah nutrisi A, wadah nutrisi B dan beberapa komponen untuk membangun pengirigasian pada tanaman aeroponik yaitu mist nozzle sprayer, selang $6 \mathrm{~mm}$. Sehingga menjadi bentuk dari alat yang sudah didesain pada tahap perancangan. Tahap berikutnya yaitu pemasangan semua komponen elektronik pada masing-masing mikrokontroler yang telah dirancang sebelumnya pada tahap skema rangkaian. Semua sensor dan modul yang dihubungkan dengan Arduino Mega 2560 digabungkan pada kotak hitam sebagai wadah untuk komponen elektroniknya.

Sensor TDS dihubungkan dengan kabel sepanjang $50 \mathrm{~cm}$ dari wadah komponen untuk diletakkan di dalam wadah nutrisi. Sensor TDS dihubungkan dengan motor servo menggunakan holder pada aktuator sehingga sensor TDS ditopang oleh aktuator. Aktuator ini dibuat linear sesuai dengan kebutuhan pada pembangunan sistem yaitu penggerak untuk mengangkat dan mencelupkan sensor pada larutan nutrisi. Sensor ultrasonik diletakkan di tutup wadah larutan nutrisi guna untuk mengukur ketinggian larutan nutrisi dan dihubungkan dengan kabel sepanjang $50 \mathrm{~cm}$ dari wadah komponen. Selanjutnya yaitu tahap pembuatan program. Program dibuat menggunakan perangkat lunak Arduino IDE untuk memprogram Arduino Mega. Setelah itu kode program diunggah ke dalam mikrokontroler agar mikrokontroler dapat berfungsi sesuai dengan kebutuhannya. Bentuk alat yang telah dibangun dapat dilihat pada Gambar 6 .

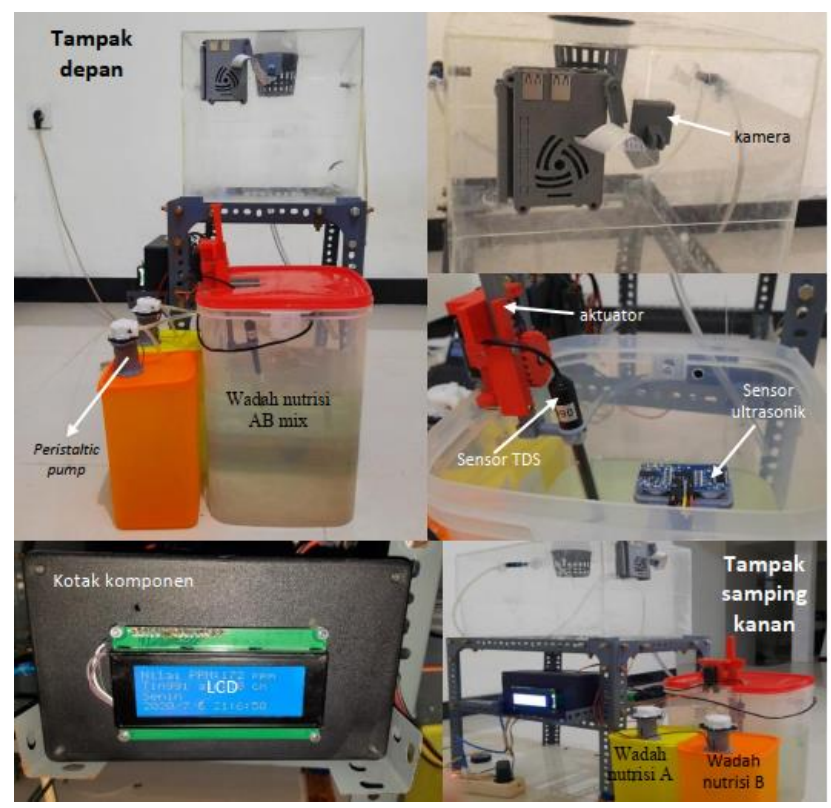

Gambar 6 Perakitan alat sistem pengaturan nutrisi dan pemantauan pertumbuhan.

Setelah sistem dirakit, dilakukan kalibrasi pada sensor yang digunakan. Kalibrasi sensor dilakukan dengan cara membandingkan nilai keluaran sensor dengan alat ukur standar (Ibrahim et al. 2015). Metode yang digunakan yaitu dengan cara mengukur larutan dengan sensor dan alat ukur. Selanjutnya, hubungan antara nilai keluaran sensor dengan alat ukur dapat diketahui melalui perhitungan regresi linear dan perhitungan koefisien korelasi. Regresi linear digunakan untuk mendapatkan nilai fungsi hasil kalibrasi dari perbandingan nilai keluaran alat (Nicola 2015) (Rozaq et al. 2020). 
Proses pengujian sensor dilakukan untuk mengetahui apakah nilai yang didapat dari sensor TDS dapat sesuai dengan alat ukur yang sudah memenuhi standar. Sebelum dilakukan pengujian perlu dilakukan kalibrasi pada sensor TDS agar nilai keluaran yang dihasilkan memiliki nilai yang sama dengan alat ukur yang sudah memenuhi standar. Sensor yang digunakan pada pembangunan alat ini adalah sensor TDS DFRobot tipe modul V2 K=1 dan alat ukur yang digunakan adalah TDS meter standar. Sensor dikalibrasi dengan menggunakan metode membandingkan hasil pengukuran TDS meter dengan nilai keluaran sensor TDS. Dari kalibrasi yang telah dilakukan didapatkan data hasil kalibrasi yang dapat dilihat pada Tabel 9 dan Gambar 7 menunjukkan hasil kalibrasi sensor TDS.

Koefisien korelasi yang didapatkan berdasarkan data tersebut yaitu 0.993. Hal ini menunjukan korelasi antara sensor dengan alat ukur sangat kuat sehingga dapat digunakan sebagai alat ukur. Berdasarkan nilai tersebut didapatkan fungsi linear untuk mengubah nilai pembacaan sensor menjadi nilai hasil kalibrasi, yaitu $y=3.3055 x-548.4$.

\begin{tabular}{ccc}
\multicolumn{3}{c}{ Tabel 9 Data kalibrasi sensor } \\
\hline No & Sensor TDS $(X)$ & TDS Meter $(Y)$ \\
\hline 1 & 311 & 518 \\
2 & 355 & 613 \\
3 & 401 & 733 \\
4 & 480 & 1025 \\
5 & 528 & 1228 \\
\hline
\end{tabular}

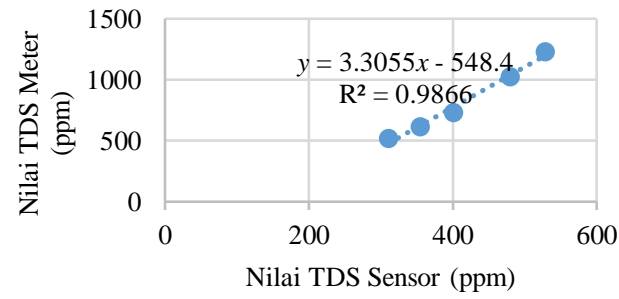

Gambar 7 Hasil Kalibrasi Sensor TDS.

Kalibrasi sensor ultrasonik dilakukan untuk menentukan jarak sensor dari permukaan larutan. Sensor ultrasonik memancarkan gelombang suara dengan frekuensi $40 \mathrm{kHz}$ yang dibangkitkan oleh transmitter. Ketika gelombang suara menyentuh permukaan objek, gelombang suara tersebut akan dipantulkan kembali dan diterima oleh receiver (Arief 2011). Perhitungan jarak berdasarkan perbedaan waktu kirim oleh transmitter dan terima oleh receiver menggunakan Persamaan 3.

$$
s=v \times \frac{t}{2}
$$

dengan s adalah jarak yang akan dihitung $(\mathrm{m}), v$ adalah kecepatan gelombang suara yaitu 340 $\mathrm{m} / \mathrm{s}$, dan $\mathrm{t}$ adalah waktu yang diperlukan saat pemancaran dan pemantulan gelombang (s).

\section{Pengujian dan Evaluasi Sistem}

Pengujian sensor TDS dilakukan dengan menggunakan 10 buah sampel larutan dengan kadar terlarut yang berbeda. Pengambilan data dilakukan sebanyak 3 kali perulangan. Larutan tersebut diukur dengan TDS meter standar dan selanjutnya diukur dengan menggunakan sensor TDS. Nilai hasil pembacaan sensor TDS dibandingkan dengan hasil pembacaan kadar larutan nutrisi menggunakan alat ukur TDS. Tabel 10 menunjukan hasil pembacaan sensor dan alat ukur TDS. Perhitungan kesalahan relatif menggunakan Persamaan 1. Nilai rata-rata kesalahan relatif yang didapatkan berdasarkan data tersebut yaitu sebesar $1.72 \%$. Nilai tersebut menunjukan bahwa nilai hasil pembacaan sensor TDS yang digunakan memiliki akurasi sebesar $98.28 \%$.

Pengujian sensor ultrasonik dilakukan dengan membandingkan hasil pembacaan sensor ultrasonik dengan penggaris. Pengujian dilakukan sebanyak tujuh kali pada jarak benda yang berbeda. Pengujian sensor ultrasonik dilakukan dengan mengukur jarak benda terhadap tembok lalu dibandingkan dengan nilai yang diukur oleh penggaris. Hasil yang diperoleh dari pengujian sensor ultrasonik sudah sesuai dengan alat acuan yang dapat dilihat pada Tabel 11. 
Tabel 10 Pengujian sensor TDS

\begin{tabular}{|c|c|c|c|c|c|c|}
\hline \multirow{2}{*}{ Sampel } & \multirow{2}{*}{$\begin{array}{l}\text { TDS meter } \\
(\mathrm{ppm})\end{array}$} & \multicolumn{3}{|c|}{ Pengukuran berulang ke- } & \multirow{2}{*}{$\begin{array}{c}\text { Rata-rata TDS sensor } \\
(\mathrm{ppm})\end{array}$} & \multirow{2}{*}{$\begin{array}{l}\text { Kesalahan } \\
\text { relatif }(\%)\end{array}$} \\
\hline & & $1(\mathrm{ppm})$ & $2(\mathrm{ppm})$ & $3(\mathrm{ppm})$ & & \\
\hline Air Mineral 1 & 177 & 179 & 187 & 180 & 182.33 & 3.01 \\
\hline Air Mineral 2 & 221 & 230 & 227 & 241 & 232.67 & 5.27 \\
\hline Larutan AB Mix 1 & 540 & 543 & 546 & 565 & 551.33 & 2.09 \\
\hline Larutan AB Mix 2 & 876 & 878 & 880 & 885 & 881 & 0.57 \\
\hline Larutan AB Mix 3 & 1015 & 1010 & 1021 & 1027 & 1019.33 & 0.42 \\
\hline Larutan AB Mix 4 & 1094 & 1089 & 1110 & 1121 & 1106.67 & 1.15 \\
\hline Larutan AB Mix 5 & 1370 & 1376 & 1377 & 1382 & 1378.33 & 0.60 \\
\hline Larutan AB Mix 6 & 1430 & 1432 & 1446 & 1454 & 1444 & 0.97 \\
\hline Larutan AB Mix 7 & 1560 & 1540 & 1567 & 1572 & 1559.67 & 0.02 \\
\hline \multirow{2}{*}{ Larutan AB Mix 8} & 1840 & 1784 & 1865 & 1980 & 1868 & 1.52 \\
\hline & & & & & Rata-rata & 1.72 \\
\hline
\end{tabular}

Tabel 11 Pengujian sensor ultrasonik

\begin{tabular}{ccccc}
\hline No & $\begin{array}{c}\text { Jarak benda (diukur } \\
\text { penggaris) }(\mathrm{cm})\end{array}$ & Sensor ultrasonik $(\mathrm{cm})$ & Selisih & Keterangan \\
\hline 1 & 5 & 5 & 0 & Sesuai \\
2 & 6 & 6 & 0 & Sesuai \\
3 & 7 & 7 & 0 & Sesuai \\
4 & 8 & 8 & 0 & Sesuai \\
5 & 9 & 9 & 0 & Sesuai \\
6 & 10 & 10 & 0 & Sesuai \\
7 & 11 & 11 & 0 & Sesuai \\
\hline
\end{tabular}

Pengujian aktuator dilakukan pada kondisi pompa dan servo. Tabel 12 menunjukan status pompa berdasarkan kadar larutan nutrisi (ppm). Pompa larutan pekatan A, pompa larutan pekatan B, dan pompa air akan menyala ketika kadar larutan nutrisi dibawah ambang batas (1250 ppm). Pompa tersebut akan berhenti ketika kadar larutan yang dibaca berada di rentang $1250 \mathrm{ppm}$ sampai $1850 \mathrm{ppm}$. Jika kadar larutan nutrisi campuran berada diatas ambang batas (> $1850 \mathrm{ppm}$ ), pompa air akan menyala, namun pompa larutan pekatan A dan pompa larutan pekatan B tetap mati.

Tabel 13 menunjukan status pompa berdasarkan jarak sensor terhadap permukaan larutan nutrisi campuran $(\mathrm{cm})$. Ketika jarak sensor terhadap larutan kurang dari sama dengan $7 \mathrm{~cm}$, pompa larutan pekatan A, pompa larutan pekatan B, dan pompa air akan tetap mati. Sebaliknya, ketika jarak sensor terhadap larutan lebih besar sama dengan $10 \mathrm{~cm}$, pompa larutan pekatan A, pompa larutan pekatan B dan pompa air akan menyala. Hal ini bertujuan untuk menjaga volume larutan nutrisi campuran agar tidak berkurang atau melebihi kapasitas wadah nutrisi.

Tabel 12 Status pompa berdasarkan nilai ppm

\begin{tabular}{lccc}
\hline \multirow{2}{*}{$\begin{array}{c}\text { Kadar nutrisi } \\
(\mathrm{ppm})\end{array}$} & \multicolumn{3}{c}{ Status pompa } \\
\cline { 2 - 4 } & Pompa & Pompa & $\begin{array}{c}\text { Pompa } \\
\text { air }\end{array}$ \\
\hline$<1250$ & HIGH & HIGH & LOW \\
$1250-1850$ & LOW & LOW & LOW \\
$>1850$ & LOW & LOW & HIGH \\
\hline
\end{tabular}

Tabel 13 Status pompa berdasarkan jarak

\begin{tabular}{lccc}
\hline \multirow{2}{*}{$\begin{array}{c}\text { Jarak sensor } \\
\text { terhadap larutan } \\
(\mathrm{cm})\end{array}$} & \multicolumn{3}{c}{ Status pompa } \\
\cline { 3 - 5 } & Pompa & Pompa & $\begin{array}{c}\text { Pompa } \\
\text { A }\end{array}$ \\
\hline$<=7$ & BOW & LOW & LOW \\
$>=10$ & HIGH & HIGH & HIGH \\
\hline
\end{tabular}

Sensor TDS dapat bergerak naik dan turun dengan menggunakan perputaran servo. Gerakan putar yang dilakukan oleh servo yang digunakan yaitu $180^{\circ}$ dan $0^{\circ}$. Pengujian dilakukan dari pukul 06.00 WIB sampai pukul 12.00 WIB. Ketika waktu memasuki jam kerja genap maka servo akan berputar $180^{\circ}$ dan sensor TDS bergerak turun ke wadah nutisi. Ketika waktu memasuki jam kerja ganjil, servo akan berputar $0^{\circ}$ dan sensor TDS bergerak naik keatas permukaan wadah nutrisi. Hasil pengujian ditunjukkan pada Tabel 14. 
Tabel 14 Kondisi servo berdasarkan waktu

\begin{tabular}{ccl}
\hline Waktu & Kondisi servo & \multicolumn{1}{c}{ Keterangan } \\
\hline $06: 00$ & $180^{\circ}$ & Servo berputar $180^{\circ}$, sensor TDS bergerak turun ke wadah nutrisi \\
$07: 00$ & $0^{\circ}$ & Servo berputar $0^{\circ}$, sensor TDS bergerak naik keatas permukaan wadah nutrisi \\
08:00 & $180^{\circ}$ & Servo berputar $180^{\circ}$, sensor TDS bergerak turun ke wadah nutrisi \\
$09: 00$ & $0^{\circ}$ & Servo berputar $0^{\circ}$, sensor TDS bergerak naik keatas permukaan wadah nutrisi \\
10:00 & $180^{\circ}$ & Servo berputar $180^{\circ}$, sensor TDS bergerak turun ke wadah nutrisi \\
11:00 & $0^{\circ}$ & Servo berputar $0^{\circ}$, sensor TDS bergerak naik keatas permukaan wadah nutrisi \\
12:00 & $180^{\circ}$ & Servo berputar $180^{\circ}$, sensor TDS bergerak turun ke wadah nutrisi \\
\hline
\end{tabular}

Setelah dilakukan pengujian pada masing-masing parameter, selanjutnya dilakukan pengujian dan pengukuran keseluruhan parameter secara bersamaan. Hal ini bertujuan untuk mengetahui kondisi fungsi dari sistem yang dibuat. Pengujian sistem dilakukan mulai pukul 06.00 WIB sampai pukul 12.00 WIB. Tabel 15 menunjukan hasil pengujian keseluruhan sistem. Berdasarkan Tabel 15, sistem pengaturan kadar larutan nutrisi pada budidaya kentang aeroponik bekerja dengan baik sesuai dengan rancangan yang dibuat.

Tabel 15 Pengujian keseluruhan sistem

\begin{tabular}{ccccccc}
\hline $\begin{array}{c}\text { Waktu } \\
(\text { WIB })\end{array}$ & $\begin{array}{c}\text { Kadar nutrisi } \\
(\mathrm{ppm})\end{array}$ & $\begin{array}{c}\text { Jarak } \\
(\mathrm{cm})\end{array}$ & Kondisi servo & Pompa A & Pompa B & Pompa Air \\
\hline $06: 00$ & 1047 & 9 & $180^{\circ}$ & HIGH & HIGH & HIGH \\
$07: 00$ & 1410 & 7 & $0^{\circ}$ & LOW & LOW & LOW \\
$08: 00$ & 1410 & 7 & $180^{\circ}$ & LOW & LOW & LOW \\
$09: 00$ & 1415 & 7 & $0^{\circ}$ & LOW & LOW & LOW \\
10:00 & 1423 & 0 & $180^{\circ}$ & LOW & LOW & LOW \\
$11: 00$ & 1423 & 0 & $0^{\circ}$ & LOW & LOW & LOW \\
12:00 & 1423 & 0 & $180^{\circ}$ & LOW & LOW & LOW \\
\hline
\end{tabular}

\section{SIMPULAN}

Sistem pengaturan nutrisi pada budidaya kentang secara aeroponik telah berhasil dikembangkan. Prototipe pengaturan kadar larutan campuran secara otomatis pada sistem telah berhasil dibuat. Sistem dapat mengatur kadar larutan nutrisi pada wadah larutan campuran secara otomatis dengan cara mengukur kadar larutan menggunakan sensor TDS. Ketika larutan campuran memiliki kadar yang lebih rendah atau lebih tinggi dari ambang batas, maka sistem akan mencampurkan larutan pekatan A, larutan pekatan B, dan air secara otomatis sampai mencapai rentang yang telah diatur sebelumnya. Sensor TDS mampu mengukur kadar larutan nutrisi campuran dengan akurasi 98.28\%. Selain itu, sensor ultrasonik mampu membaca ketinggian air sesuai dengan jarak yang sesungguhnya pada semua pengujian yang dilakukan. Aktuator pergerakan sensor TDS bekerja sesuai dengan skenario yang dikembangkan. Pergerakan tersebut ditujukan untuk memperpanjang usia guna dari sensor yang digunakan. Aktuator bergerak turun ke arah larutan nutrisi ketika jam sistem benilai genap dan bergerak ke atas ketika jam sistem bernilai ganjil. Berdasarkan hasil pengujian, sistem secara keseluruhan dapat bekerja dengan baik sesuai dengan rancangan yang dibuat. Saat ini, sistem hanya memiliki satu buah lubang tanam, namun agar dapat diaplikasikan pada lingkungan produksi diperlukan penambahan jumlah lubang tanam dan sprayer.

\section{DAFTAR PUSTAKA}

[BPS] Badan Pusat Statistik. 2015. Statistik Indonesia 2015. Jakarta (ID): Badan Pusat Statistik. Amsah A. 2017. Respon pertumbuhan dan produksi bibit tanaman kentang (Solanum tuberosum

L) terhadap pemberian berbagai konsentrasi nutrisi Adan B Mix secara aeroponik [Skripsi]. Medan (ID): Universitas Medan Area.

Arief UM. 2011. Pengujian sensor ultrasonik PING untuk pengukuran level ketinggian dan volume air. Jurnal Ilmiah Elektrikal Enjiniring. 9(2): 72-77. 
Dianawati M. 2013. Produksi benih umbi mini kentang (Solanum tuberosum L.) secara aeroponik dengan induksi pengumbian [disertasi]. Bogor (ID): Sekolah Pascasarjana Institut Pertanian Bogor.

Diwa AT, Dianawati M, Sinaga A. 2015. Petunjuk Teknis Budidaya Kentang. Lembang (ID): Repositori Kementrian Pertanian

Gunawan H. Inovasi baru perbanyakan bibit kentang G-0 sistem aeroponik. Pusat Inkubator Agribisnis BBPP Lembang. 2009;2.

Ibrahim MNR, Solahudin M, Widodo S. 2015. Control system for nutrient solution of nutrient film technique using fuzzy logic. Tekomnika. 13(4): 1281-288.

Kerns SC, Lee JL. 2017. Automated aeroponics system using IoT for smart farming. Di dalam: 8th International Scientific Forum; Pembroke, 2017 Sep 7-8. Pembroke (USA). hlm: 104110.

Mbiyu MW. 2012. Use of aeroponics technique for potato (Solanum tuberosum) minitubers production in Kenya. Journal of Hotriculture and Foresty. 4(11):172-177.

Montoya AP, Obando FA, Morales JG, Vargas G. 2017. Automatic aeroponic irrigation system based on Arduino's platform. Journal of Physics: Conference Series. 850)1):012003.

Otazu V. 2010. Manual on Quality Speed Potato Production using Aeroponics. Peru (PE): the CIP Communication and Public Awareness Department (CPAD).

Rozaq IA, Setyaningsih NY, Gunawan B. 2020. Pengkondisian sinyal sensor salinitas Dfr0300 menggunakan arduino Due. Proceeding SENDIU 2020; Semarang, 2020 Jul 22. Semarang (ID). hlm: 459-463.

Ruchjaniningsih R, Thamrin M, Wahid A. 2019. Kajian perbanyakan produksi umbi bibit kentang melalui sistem aeroponik dalam mendukung ketersediaan bibit unggul di Sulawesi Selatan. Di dalam: Buletin Inovasi Teknologi Pertanian No 15 Tahun 2019. Makassar (ID): Balai Pengkajian Teknologi Pertanian Sulawesi Sulatan.

Setiawan A. 2019. Buku Pintar Hidroponik. Yogyakarta (ID): Laksana.

Setyorini B. 2012. Analisis kepadatan penduduk dan proyeksi kebutuhan permukiman Kecamatan Depok Sleman tahun 2010-2015 [disertasi]. Surakarta (ID): Universitas Muhammadiyah Surakarta.

Siregar SL, Rivai M. 2019. Monitoring dan kontrol sistem penyemprotan air untuk budidaya aeroponik menggunakan NodeMCU ESP8266. Jurnal Teknik ITS. 7(2):A380-5.

Sumarni EH, Suhardiyanto KB, Saptomo SK. 2013. Pendinginan zona perakaran (root zone cooling) pada produksi benih kentang menggunakan sistem aeroponik. Jurnal Agronomi Indonesia. 41(2): 154-159.

Sutiyoso Y. 2003. Aeroponik Sayuran. Budidaya dengan Sistem Pengabutan. Jakarta (ID): Penebar Swadaya.

Sutrisna N, Lembang B. 2014. Kajian formula pupuk NPK pada pertanaman kentang lahan dataran tinggi di Lembang Jawa Barat. J. Hort. 24(2):124-132.

Ummah K, Purwito A. 2009. Budidaya tanaman kentang (Solanum tuberosum L.) dengan aspek khusus pembibitan di Hikmah Farm, Pangalengan, Bandung, Jawa Barat. Bogor (ID): Institut Pertanian Bogor.

Utami GR, Rahayu MS, Setiawan A. Penanganan budidaya kentang (Solanum tuberosum L.) di Bandung, Jawa Barat. Buletin Agrohorti. 3(1):105-109.

Zulfikar A, Paring G. 2016. Sistem otomasi perawatan sensor $\mathrm{pH}$ pada peralatan monitoring kadar $\mathrm{pH}$ [skripsi]. Surabaya (ID): Institut Teknologi Sepuluh Nopember. 